\title{
Investigation on the in vitro antioxidant capacity of methanol extract, fractions and flavones from Oroxylum indicum Linn bark
}

\author{
Do Hoang Thu Trang ${ }^{1}$, Hoang Le Son ${ }^{*}$, Phung Van Trung ${ }^{2}$
}

\author{
${ }^{1}$ Department of Applied Biochemistry, International University, Vietnam National University, Ho Chi Minh City, Vietnam, \\ ${ }^{2}$ Institute of Chemical Technology, Vietnam Academy of Science and Technology, Vietnam
}

\begin{abstract}
Antioxidants from natural sources hold high values regarding their indispensible roles in the development of nutraceuticals, pharmaceuticals and cosmetic products. Oroxylum indicum L. is a common medicinal plant with a wide range of therapeutic properties, including a notable antioxidant potency that was reported, yet has not been subjected to more detailed studies. The present study evaluated the potency of Oroxylum indicum methanol stem bark extract, along with its hexane, ethyl acetate, methanol fractions, three flavones including baicalein, oroxylin A and chrysin using DPPH assay. In terms of $\mathrm{IC}_{50}$ values, the crude extract $(65,48 \mu \mathrm{g} / \mathrm{mL})$ exhibited moderate inhibitory activity which was as half potent as that of its ethyl acetate fraction $(32,94 \mu \mathrm{g} / \mathrm{mL})$. This fraction was also superior to the methanol and hexane fractions, as their $\mathrm{IC}_{50}$ were 57,19 and $137,95 \mu \mathrm{g} / \mathrm{mL}$ respectively. Remarkably, a yellow powdery sub-fraction consisted of isolated compounds showed powerful activity $(32,89 \mu \mathrm{g} / \mathrm{mL})$ compared to those of its components, revealing the intriguing effect of synergism while giving evidence for the theory of structure-activity relationship between some flavones and their antioxidant capability. Perpetual search for new radical scavenging agents in Oroxylum indicum is emboldened considering its partially exploited potential in this study.
\end{abstract}

Keywords: Oroxylum indicum. Flavones. Methanol/extract. DPPH assay. Antioxidants. Inhibitory Concentration 50. Bignoniaceae.

\section{INTRODUCTION}

Oxidation is a critical metabolic process thanks to which a body can perform living functions properly. The oxidative metabolism however produces reactive oxygen species (ROS) that in case of highly accumulated, would create oxidative stress that damages cell structure, contributing to pathogenesis of most inflammatory diseases, cardiovascular diseases, neurodegenerative diseases and cancers by attacking biologically relevant molecules (Hensley et al., 2000). Although a body has its own systems to balance the ratio between oxidants and antioxidants, they can get overwhelmed sometimes like every other machinery. Therefore, the supplement of antioxidants is undoubtedly of great importance, as searches for agents with free radicals scavenging activity have been carried out continually. (Brand-Williams, Cuvelier, Berset, 1995; Koleva et al., 2002)

\footnotetext{
*Correspondence: H. L. Son. Department of Applied Biochemistry, International University, Vietnam National University, Quarter 6, Linh Trung Ward, Thu Duc District, Ho Chi Minh City, Vietnam. Email: hlson@hcmiu.edu.vn
}

Oroxylum indicum L. (Bignoniceae) is a commonly known medicinal plant that distributes throughout the territory of Vietnam, particularly in the Southern and the Central Highlands of Vietnam. Each part of the plant can be utilized as remedies for various diseases. The root bark is an astringent and bitter tonic that can alleviate bronchitis, diarrhea, diaphoretism and rheumatism (Khandhar et al., 2008; Zaveri, Jain, 2009). O. indicum seeds are used in treating stomach disorders, pneumonia, and wounds (Dev, Anurag, Rajiv, 2010; Joshi, Alok, Tapan, 2014). The bark can reduce severity of diarrhea, dysentery, coilitis and skin conditions such as ulcer and eczema (Khandhar et al., 2008; Vikrant, Arya 2011). Fruits of $O$. indicum are useful for treating haemarrhoids, cholera and leukoderma (Joshi, Alok, Tapan, 2014). A large number of pharmacological reports on $O$. indicum L. have been conducted. The root bark was shown to have various bioactivities such as antimicrobial, antiulcer, immunomodulatory, antihyperlipidemic, antimicrobial, cytotoxic, and apoptotic effects. Other parts of the plant were also proven to have valuable bioactivities, including the leaves with hepatoprotective effect, and fruits with 
antimutagenic effect (Dev, Anurag, Rajiv, 2010; Bisht et al., 2011). Such a wide range of bioactivities may be attributed to $O$. indicum's phytochemical composition with a high amount of tannins, glycosides, phenolics, phenolic acids, and flavonoids. The leaves of $O$. indicum were reported to contain four flavonoids: chrysin, hispidulin, baicalein and oroxylin A by Hương et al. (2013), and quercetin-3-o- $\alpha$ - L-arabinopyranoside, 1-(2-hydroxyethyl) cyclohexane-1, 4-diol and apigenin by Yuan et al. (2008). From the seeds of the plants, chrysin, baicalein, baicalein7-O-glucoside (Oroxin A) and baicalein-7-O-diglucoside (Oroxylin B) were isolated (Chen, Games, Jones, 2003). Ellagic acid and biochanin-A were also found in the root bark of $O$. indicum (Zaveri, Khandhar, Jain, 2008). The fruits were reported to contain ursolic acid and aloeemodin besides its main phytocomponents (Yuan et al., 2008). Thanks to this variety of bioactive compounds in the plant composition, $O$. indicum is highly appreciated as a valuable herbal medicine in Vietnam.

Plant is the primary source of antioxidants that are affordable and easily accessible especially in Vietnam, a country endowed with extremely rich flora abundance. Containing high content of phenolics and flavonoids, $O$. indicum therefore has high potential as a strong antioxidant agent. The screening for antioxidant activities of the plant extract from different parts using various solvents is, however, still preliminary and needs to be furthered. It is definitely crucial to conduct this study, considering our long-term national developing schemes with serious focuses on the fostering and conservation of phytomedicines in particular regions, such as the Mekong Delta or the Central Highlands of Vietnam. Indeed, the reevaluation on this specific plant's bioactivity is indispensable for numerous sustainable forest and agricultural management programs in this mission as it certainly will add highlights to the true values and potentials of this medicinal plant. The present study, accordingly, aims to extend the knowledge on the antioxidant activity of $O$. indicum bark by investigating the total methanolic extract, its hexane, ethyl acetate and methanol fractions, 3 pure compounds isolated from the extract and the combination of these by DPPH free radical scavenging assay.

\section{MATERIAL AND METHODS}

\section{Chemicals and reagents}

Methanol, ethanol, hexane, ethyl acetate, and chloroform were purchased from Fischer Scientific. 2,2-Diphenyl-1-picryl-hydrazyl (DPPH) and ascorbic acid for DPPH assay were supplied by from Sigma-Aldrich.
HPLC grade methanol, dimethyl sulfoxide (DMSO) and silica gel $\mathrm{F}_{254}$ aluminium sheets for TLC was obtained from Merck. Silica gel KG 60 (0.040-0.063 mm) (Scharlau) was used for column chromatography.

\section{Collection and preparation of plant materials}

O. indicum stem bark was obtained in Dak Lak, the high mountain central of Vietnam, 2016, and immediately washed with tap water to eliminate possible contaminants. The plant was authenticated by Associate Professor Tran Van Minh of the Institute of Tropical Biology, Vietnam and a voucher specimen (No. HBBIO-06-08-1) has been deposited in the herbarium of Applied Biochemistry Laboratory, Department of Applied Biochemistry, School of Biotechnology, International University, Vietnam National University - Ho Chi Minh City, Vietnam. The preparation of plant extracts, isolation of compounds and assessment of DPPH scavenging activity were carried out in the Institute of Chemical Technology - Vietnam Academy of Science and Technology, Ho Chi Minh City, Vietnam. The bark was dried in the oven at $65^{\circ} \mathrm{C}$ for 3 days and finely ground before being exhaustively macerated with 10 liters of methanol. This crude extract (CE) was subjected to filtration using Whatmann filter paper No. $42(125 \mathrm{~mm})$ and concentrated using rotary evaporator.

\section{Partition of the total extract}

The crude extract (165 g) was later successively partitioned with $5 \mathrm{~L}$ of n-hexane which was added in small portions. Within each time, the mixture was vigorously agitated for 5 minutes using a sonicator. The hexane layer was collected and condensed as hexane fraction (HF). In a similar manner, the partition of the remaining extract with 10 L of ethyl acetate was carried out exhaustively. The extract collected in this step was identified as ethyl acetate fraction (EAF). The remained was identified as methanol fraction (MF). All extracts were concentrated under high pressure and stored at $4{ }^{\circ} \mathrm{C}$ for further separation and analysis.

\section{Fractionation of EA extract}

For the fractionation, EAF was chromatographed on a glass column $(\mathrm{d}=7 \mathrm{~cm}, 1=45 \mathrm{~cm})$ packed with 370 g silica gel KG 60 (0.040-0.063 mm) (Scharlau). An amount of $20 \mathrm{~g}$ of EAF was mixed with silica gel (mass ratio 1:1) and applied into the prepared column that was later eluted by a gradient solvent system including hexane, ethyl acetate and methanol. The collected fractions were examined by TLC so that main components of each were 
exposed. After the elution with hexane-ethyl acetate $(3: 1$ and 1:1), a yellow powder, namely EAF-sub, was collected and chosen to be subjected to further separation as its chromatogram revealed only 4 visible bands at relatively different $\mathrm{Rf}$ when developed in a saturated TLC chamber containing chloroform.

\section{Isolation and identification of compounds (1), (2) and (3)}

EAF-s was dissolved completely in methanol, injected to a semi-prep HP 1050 HPLC system and separated using an Agilent ZORBAX Eclipse XDB-C18 column $(21.2 \times 150 \mathrm{~mm}$, particle size $5 \mu \mathrm{m})$. The solvent system consisted of methanol: water (68:32) was pumped through the column at a flow rate of $8.00 \mathrm{ml} / \mathrm{min}$, while detection wavelength was set to $245 \mathrm{~nm}$. Compound (1) was from EAF-s fraction after the process, leaving another sub-fraction as the mixture of compound (2) and (3). MPLC was used in the next step for isolation of remained compounds. Specifically, compound (2) and (3) were subjected to a glass column $(\mathrm{d}=2 \mathrm{~cm} ; 1=50 \mathrm{~cm})$ packed with $80 \mathrm{~g}$ silica gel KG $60(0.040-0.063 \mathrm{~mm})$ with chloroform $(100 \%)$ as the eluent at a flow rate of $2.00 \mathrm{~mL} /$ minute. All 3 compounds (1), (2), and (3) (Figure 1) were identified from ${ }^{13} \mathrm{C}$ - and/or ${ }^{1} \mathrm{H}$ - NMR spectra recorded on a NMR Bruker Avance II spectrometer at $500 \mathrm{MHz}\left({ }^{1} \mathrm{H}\right)$ and $125 \mathrm{MHz}\left({ }^{13} \mathrm{C}\right)$, with dimethyl sulfoxide as internal standard, in reference with published literature (Yan et al., 2011; Mouffok et al., 2012; Hương et al., 2013).

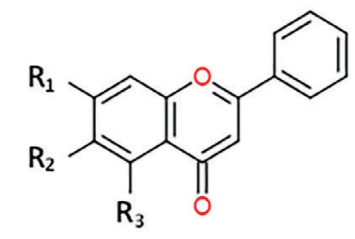

\begin{tabular}{cccc}
\hline & R1 & R2 & R3 \\
\hline $\begin{array}{c}(1) \\
\text { Baicalein }\end{array}$ & OH & OH & OH \\
\hline $\begin{array}{c}(2) \\
\text { Chrysin }\end{array}$ & OH & OCH3 & OH \\
\hline $\begin{array}{c}\text { (3) } \\
\text { Oroxylin A }\end{array}$ & OH & H & OH \\
\hline
\end{tabular}

FIGURE 1 - Chemical structures of isolated compounds in the study.

Spectral data

Baicalein (1): brownish yellow powder; M.P. 256 ${ }^{\circ} \mathrm{C}$; ${ }^{1} \mathrm{H}$ NMR (500 MHz, DMSO) $\delta 12.64$ (s, 1H), $10.63-$ $9.23(\mathrm{~m}, 1 \mathrm{H}), 8.06(\mathrm{dd}, \mathrm{J}=8.1,1.4 \mathrm{~Hz}, 2 \mathrm{H}), 7.64-7.46$ (m, 3H), $6.92(\mathrm{~s}, 1 \mathrm{H}), 6.63(\mathrm{~s}, 1 \mathrm{H})$.

Oroxylin A (2): light yellow powder; M.P. $202^{\circ}$ C; ${ }^{1} \mathrm{H}$ NMR (500 MHz, DMSO) $\delta 12.78$ (s, 1H), 8.04 (dd, $\mathrm{J}=8.0,1.3 \mathrm{~Hz}, 2 \mathrm{H}), 7.78-7.45(\mathrm{~m}, 3 \mathrm{H}), 6.87(\mathrm{~s}, 1 \mathrm{H})$, $6.41(\mathrm{~d}, \mathrm{~J}=1.6 \mathrm{~Hz}, 1 \mathrm{H}), 6.11(\mathrm{~d}, \mathrm{~J}=1.7 \mathrm{~Hz}, 1 \mathrm{H}), 3.70$ (s, $1 \mathrm{H}), 3.17$ (s, $1 \mathrm{H}) ;{ }^{13} \mathrm{C}$ NMR (126 MHz, DMSO) $\delta 181.87$, $162.83,152.73,152.50,131.85,130.85,129.10,126.29$, $104.57,94.62,59.77$.

Chrysin (3): yellow powder; M.P. $284{ }^{\circ} \mathrm{C} ;{ }^{1} \mathrm{H}$ NMR (500 MHz, DMSO) $\delta 12.89(\mathrm{~s}, 1 \mathrm{H}), 8.05$ (dd, J = 8.1, 1.4 $\mathrm{Hz}, 2 \mathrm{H}), 7.69-7.46(\mathrm{~m}, 3 \mathrm{H}), 6.91(\mathrm{~s}, 1 \mathrm{H}), 6.56(\mathrm{~s}, 1 \mathrm{H})$, $3.79-2.55(\mathrm{~m}, 18 \mathrm{H}), 2.50(\mathrm{tt}, \mathrm{J}=12.0,6.0 \mathrm{~Hz}, 8 \mathrm{H}), 1.99$ $(\mathrm{s}, 1 \mathrm{H}), 1.62-1.34(\mathrm{~m}, 1 \mathrm{H}), 1.26(\mathrm{~d}, \mathrm{~J}=24.3 \mathrm{~Hz}, 6 \mathrm{H}), 1.16$ $(\mathrm{dd}, \mathrm{J}=24.0,6.7 \mathrm{~Hz}, 1 \mathrm{H}), 0.97-0.58(\mathrm{~m}, 2 \mathrm{H}) ;{ }^{13} \mathrm{C} \mathrm{NMR}$ (126 MHz, DMSO) $\delta 181.25,167.68,162.52,161.33$, $157.66,131.75,130.94,129.09,126.24,104.94,102.75$, $99.79,94.54$.

\section{In vitro antioxidant activity}

In vitro antioxidant activity of isolated compounds was investigated using DPPH free radical scavenging assay with slight modifications (Amin, Norazaidah, Emmy, 2006). Briefly, testing samples of CE, HF, MF, EAF, EAF-sub, compounds (1), (2) and (3) were prepared in various concentrations $20,40,60,80$ and $100(\mu \mathrm{g} / \mathrm{mL})$ by dissolution and dilution in DMSO. Blank solution and ascorbic acid were used as negative and positive control, respectively. An aliquot of $50 \mu \mathrm{L}$ of prepared sample was then loaded into separated well. A volume of $150 \mu \mathrm{L}$ of ethanolic DPPH was added and mixed well. The mixtures were immediately incubated at room temperature, in the absence of light for 30 minutes before the absorbance at $517 \mathrm{~nm}$ were measured. The assay was performed in triplicates. The percentage of inhibition of DPPH free radical was evaluated following the below equation:

$$
\% \text { Inhibition }=(\mathrm{ODc}-\mathrm{ODs}) \times 100 \% / \mathrm{ODc}
$$

where ODc is the OD value of negative control and ODs is the OD value of testing sample.

$\mathrm{IC}_{50}$ value indicating the concentration at which a sample would inhibit free radicals by $50 \%$ was also calculated.

\section{Statistical analysis}

All results were expressed in terms of Mean 
\pm Standard Error of Mean (SEM). The correlation coefficients between generated data in the determination of antioxidant activity and the concentration of samples were calculated in Graph Pad Prism package 6.

\section{RESULTS AND DISCUSSION}

The potent antioxidant activity of $O$. indicum has been recognized through some significant studies. Different parts of the plant were proven to possess scavenging ability of varied potencies in a comparative study by Sannigrahi et al. (2010), in which the bark extract exhibited its superior antioxidant activity. As the search for new antioxidants has never ceased, more research subjecting $O$. indicum ethyl acetate bark extract needs to be conducted for the sake of novel and effective fractions or compounds. In this study, we aimed to confirm and report new insights into the pharmacological activities of $O$. indicum methanol bark extract and its components, particularly antioxidant effect by performing DPPH assay.

The inhibitory activity of all samples was investigated at various concentrations (Figure 2). The crude extract of the plant $(\mathrm{CE})$ has exhibited a quite remarkable activity at $100 \mu \mathrm{g} / \mathrm{mL}(63.16 \%)$. Out of the three fractions derived from this crude extract, ethyl acetate fraction (EAF) had the greatest abundance of antioxidants compared to hexane and methanol ones (HF and MF) and thus, further separation was carried out on this fraction. EAF was submitted to a silicagel column chromatography and yielded a sub-fraction that was a yellow, powdery solid in large quantity, namely EAF-sub. From this sub-fraction, three pure compounds isolated and identified based on their physical characteristics (Figure 1), TLC chromatographs and NMR spectra in reference to published literature. The compounds were then found to be baicalein, chrysin and oroxylin A. However, the radical inhibitory activity of chrysin was undetectable at all examined concentrations, when that of oroxylin A, detectable only at 20 and $80 \mu \mathrm{g} / \mathrm{mL}$, indicated a very insignificant level of activity compared to the control and baicalein. The inhibition percentage of baicalein, as found to be $45.64 \pm 1.31$, was comparatively lower than that of standard ascorbic acid $(89.70 \pm 0.17)$ at the concentration of $100 \mu \mathrm{g} / \mathrm{mL}$. The EAF-sub sample with the presence of all three compounds, nonetheless, showed surprisingly strong activity $(82.63 \pm 0.16)$ that reached almost as high as ascorbic acid's.

The antioxidant property of various extracts, fractions and constituents of $O$. indicum bark was as well presented by their $\mathrm{IC}_{50}$ values (Figure 3 ). The value of crude extract was lower than the one reported by Sannigrahi et al. (2010) (65.48 $\mu \mathrm{g} / \mathrm{mL}$ compared to $149.59 \mu \mathrm{g} / \mathrm{mL}$ ), regarding the same employed plant parts and solvents of extraction. Out of the three fractions derived from CE, EAF fraction showed the strongest antioxidant activity with its significantly smaller IC50 values in comparison with $\mathrm{HF}$ and $\mathrm{MF}$, being $32.94 \mu \mathrm{g} /$ $\mathrm{mL}, 137.95 \mu \mathrm{g} / \mathrm{mL}$ and $57.19 \mu \mathrm{g} / \mathrm{mL}$, respectively. The sub-fraction EAF-sub exhibited a quite as low IC50 as EAF (32.89 $\mu \mathrm{g} / \mathrm{mL}$ to $32.94 \mu \mathrm{g} / \mathrm{mL})$ and showed a surprisingly superior scavenging capability to those of its components, including baicalein, chrysin and oroxylin A. These naturally occurring flavones, often introduced as remarkable neuroenhancing and neuroprotecting substances (Cheng et al., 2008; Lee et al., 2010; Nabavi et al., 2015), did not exerted significant antioxidant activity singly in the present study and thus, should be utilized

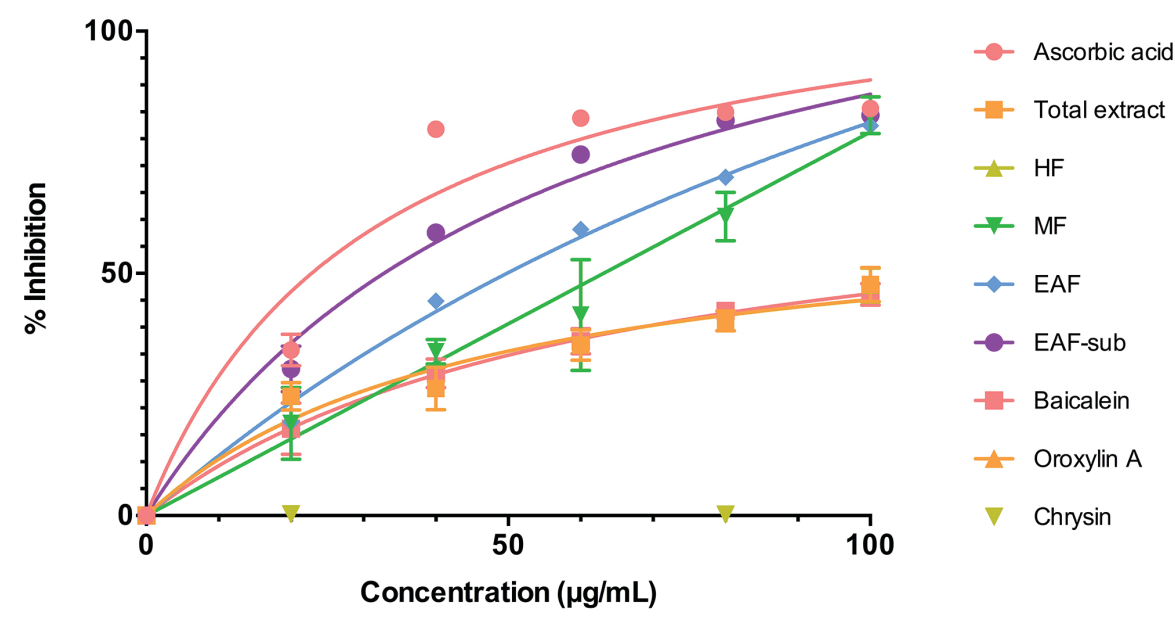

FIGURE 2 - DPPH free radical inhibiting activity (\%) at various concentration of the total extract, hexane (HF), methanol (MF) and ethyl acetate (EAF) fractions, sub-fraction of ethyl acetate fraction (EAF-sub), baicalein, oroxylin A, chrysin and ascorbic acid. - not determined. Each point represents the Mean \pm SEM. 
when combined as a mixture. This also encourages the search for novel antioxidants with outstanding potency in other components of $O$. indicum, especially the ethyl acetate and methanol fractions, as their identities might have not yet been unveiled in the present study.

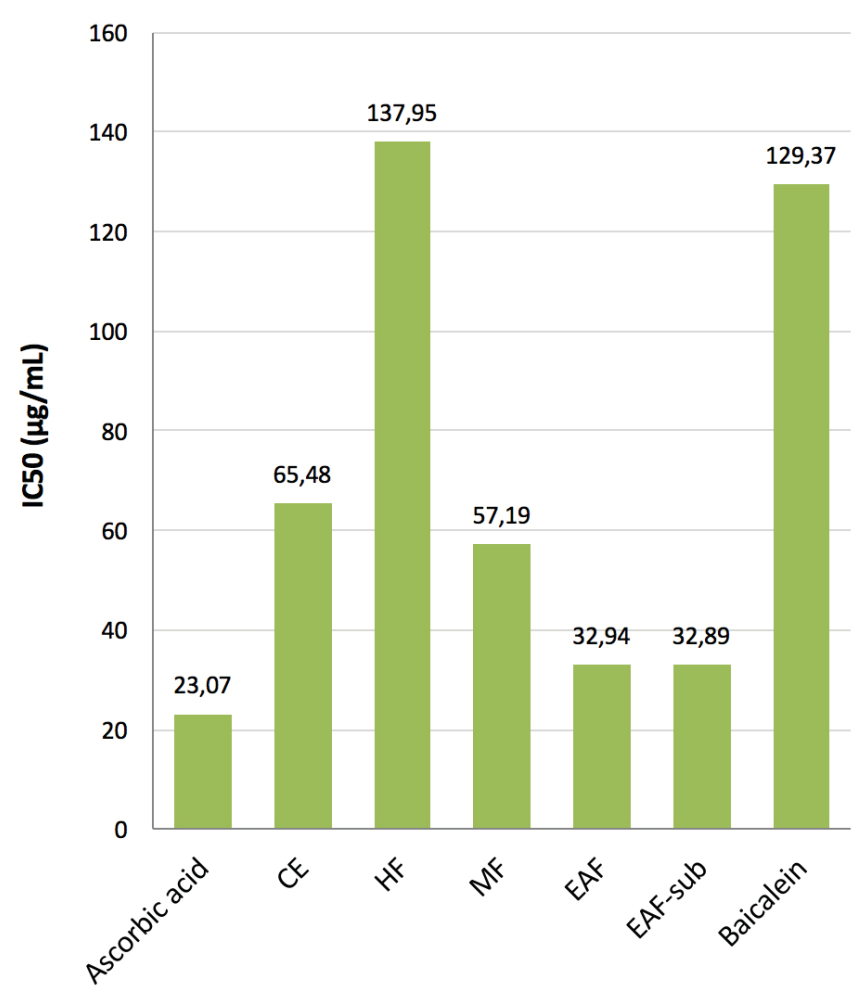

FIGURE 3 - DPPH IC50 $(\mu \mathrm{g} / \mathrm{ml})$ of the crude extract, hexane, methanol and ethyl acetate fractions, subfraction of ethyl acetate fraction, compound (1) and ascorbic acid.

The structure-activity relationship of antioxidants fell into the category of flavonoids has been in discussion for long as a tool of revelation and explanation for the capability of a substance (Rice-Evans et al., 1996). While all isolated compounds in the present study share similar features as being flavones, they are only different in the functional groups attached on 6-C, illustrating how an A-ring substitution can impact an antioxidant's potency. The superior effect of baicalein to the other two compounds might be ascribed to its 6-OH group when methoxy group at this same position might have diminished the effect of oroxylin A (Pietta, 2000; Heim, Tagliaferro, Bobilya, 2002), possibly due to an increase in hydrophobicity of the molecule as a result of $O$-methylation (Heim, Tagliaferro, Bobilya, 2002). Indeed, more studies focusing on the conformation of investigated compounds in relation with their pharmacological effects using different assays would be helpful to reach a valid conclusion.

A central metabolic process enabling the living and all functionalities of every organism as it is, oxidation unfavorably increases the amount of ROS in a condition termed "oxidative stress", and is responsible for the deterioration of many biomolecules. So as to protect the components of cells made up of proteins, lipids and nucleic acids, antioxidants come into play by forming several lines of defense against ROS and restore the balance disturbed by the stress (Hensley et al., 2000; Irshad, Chaudhuri, 2002). Many methods for detection and assessment of antioxidant activity are constructed considering the complicated nature of oxidative and antioxidative systems inside the body. The DPPH assay used in this investigation reveals whether a sample possesses scavenging action on active radicals by donating hydrogen atoms to DPPH molecules (Brand-Williams, Cuvelier, Berset, 1995). Because of its cost-saving and simple practice, together with the ability to generate data with high correlate coefficient while constructing standard curve for determination of $\mathrm{IC}_{50}$ values (Table I), DPPH assay is widely used for the assessment of drugs and foodstuffs with high antioxidant potential. It is also recommended that investigated extract and components of $O$. indicum in this present study should be tested by various assays with different types of active radicals, both in vivo and in vitro, so that their mechanisms and targets of action can be elucidated and exploited properly to the fullest.

\section{CONCLUSION}

The antioxidant property of $O$. indicum extract, its fractions and isolated flavones has been demonstrated through DPPH assay in our study. Significant differences in the scavenging ability of three fractions derived from the partition with solvents of distintive polarity, while disclosing strong antioxidants in the extract mostly are moderately or highly polar, are evidence for later studies to narrow their research down to the ethyl acetate and methanol fractions when the antioxidant profile of $O$. indicum is brought into analysis. Comparably

TABLE I - Correlation coefficient $\left(\mathrm{R}^{2}\right)$ of DPPH assay

\begin{tabular}{ccccccc}
\hline Ascorbic acid & CE & HF & MF & EAF & EAF-sub & Compound (1) \\
\hline 0.9872 & 0.9992 & 0.8626 & 0.9735 & 0.9985 & 0.9980 & 0.9980 \\
\hline
\end{tabular}


higher activity of a subfraction to those of its flavones components individually - a telltale of synergetism in free radical scavenging, and minor structural differences between such flavones that suggest a closer look to the structure-activity relationship both pave the path for more extensive research on plant-derived antioxidants.

\section{ACKNOWLEDGEMENT}

The authors are thankful to staff and personnel of Natural Product Laboratory, Institute of Chemical Technology - Vietnam Academy of Science and Technology, for their valuable support on equipment, chemicals and facilities.

\section{AUTHORS' CONTRIBUTION}

This work was carried out in collaboration between all authors. Author DHTT performed the experiment and wrote the manuscript. Authors PVT designed the study and supervised experimental process. Author HLS contributed to the conceptualization and supervision of the study, and finally to the revision of the manuscript. All authors have read and approved the final manuscript.

\section{CONSENT}

Not applicable.

\section{COMPETING INTERESTS}

Not applicable.

\section{REFERENCES}

Amin I, Norazaidah Y, Emmy HK. Antioxidant activity and phenolic content of raw and blanched Amaranthus species. Food Chem. 2006;94(1):47-52.

Bisht A, Zaman K, Singh M, Gupta R. Pharmacognostical studies on Oroxylum indicum (Linn.) Vent. stem bark. Indian J Nat Prod Resour. 2011;2(4):472-8.

Brand-Williams W, Cuvelier ME, Berset C. Use of a free radical method to evaluate antioxidant activity. LWT - Food Sci Technol. 1995;28(1):25-30.

Chen L-J, Games DE, Jones J. Isolation and identification of four flavonoid constituents from the seeds of Oroxylum indicum by high-speed counter-current chromatography. J Chromatogr A. 2003;988(1):95-105.
Cheng Y, He G, Mu X, Zhang T, Li X, Hu J, et al. Neuroprotective effect of baicalein against MPTP neurotoxicity: behavioral, biochemical and immunohistochemical profile. Neurosci Lett. 2008;441(1):16-20.

Dev LR, Anurag M, Rajiv G. Oroxylum indicum: a review. Pharmacog J. 2010;2(9):304-10.

Heim KE, Tagliaferro AR, Bobilya DJ. Flavonoid antioxidants: chemistry, metabolism and structure-activity relationships. J Nutr Biochem. 2002;13(10):572-84.

Hensley K, Robinson KA, Gabbita SP, Salsman S, Floyd RA. Reactive oxygen species, cell signaling, and cell injury. Free Radic Biol Med. 2000 May;28(10):1456-62.

Hương L, Công NT, Trang N, Trang N. Các hợp chất flavonoit từ lá cây núc nác Oroxylum indicum [Flavonoids from the leaves of Oroxylum indicum]. Tạp Chí Khoa Học. 2013;43:92-7

Irshad M, Chaudhuri PS. Oxidant-antioxidant system: role and significance in human body. Indian J Exp Biol. 2002;40(11):1233-9.

Joshi N, Alok S, Tapan KN. Taxonomic and phytomedicinal properties of Oroxylum indicum (L.) Vent: a wonderful gift of nature. J Med Plant Res. 2014;8(38):1148-55.

Khandhar M, Shah M, Santani D, Jain S. Antiulcer activity of the root bark of Oroxylum indicum against experimental gastric ulcers. Pharm Biol. 2008;44(5):363-70.

Koleva II, Van Beek TA, Linssen JPH, Groot A, Evstatieva LN. Screening of plant extracts for antioxidant activity: a Comparative study on three testing methods. Phytochem Anal. 2002;13(1):8-17.

Lee S, Kim D-H, Lee DH, Jeon SJ, Lee CH, Son KH, et al. Oroxylin A, a flavonoid, stimulates adult neurogenesis in the hippocampal dentate gyrus region of mice. Neurochem Res. 2010;35(11):1725-32.

Mouffok S, Haba H, Lavaud C, Long C. Chemical constituents of Centaurea omphalotricha Coss. \& Durieu ex Batt. \& Trab. Rec Nat Prod. 2012;6(3):292-5.

Nabavi SF, Braidy N, Habtemariam S, Orhan IE, Daglia M, Manayi A, et al. Neuroprotective effects of chrysin: from chemistry to medicine. Neurochem Int. 2015;90:224-31. 
Pietta PG. Flavonoids as antioxidants. J Nat Prod. 2000;63(7):1035-42.

Rice-Evans CA, Miller NJ, Paganga G. Structure-antioxidant activity relationships of flavonoids and phenolic acids. Free Radic Biol Med. 1996;20(7):933-56.

Sannigrahi S, Mishra SL, Sinhamahapatra PK, Nayak A, Das R. In vitro antioxidant potential of different parts of oroxylum indicum: a comparative study. Indian J Pharm Sci. 2010;72(2):267.

Vikrant A, Arya ML. A review on anti-inflammatory plant barks. Int J PharmTech Res. 2011; 3(2):899-908.

Yan R-Y, Cao Y-Y, Chen C-Y, Dai H-Q, Yu S-X, Wei J-L, et al. Antioxidant flavonoids from the seed of Oroxylum indicum. Fitoterapia. 2011;82(6):841-8.
Yuan Y, Hou W, Tang M, Luo H, Chen L-J, Guan YH, et al. Separation of flavonoids from the leaves of Oroxylum indicum by HSCCC. Chromatographia. 2008;68(11/12):885-92.

Zaveri M, Jain S. Anti-inflammatory and analgesic activity of root bark of Oroxylum indicum, Vent. J Global Pharma Technol. 2009;2(4):79-87.

Zaveri M, Khandhar A, Jain S. Quantification of Baicalein, Chrysin, Biochanin-A and Ellagic acid in root bark of Oroxylum indicum by RP-HPLC with UV detection. Eurasian J Anal Chem. 2008;3(2):245-57.

Received for publication on $09^{\text {th }}$ April 2017 Accepted for publication on $07^{\text {th }}$ August 2017 